\title{
A Farewell to Ricky Pollack
}

\author{
János $\operatorname{Pach}^{1,2,3}$
}

Published online: 20 August 2020

๑) Springer Science+Business Media, LLC, part of Springer Nature 2020

How are you, Ricky? Until the very end, whenever I called him, he answered on the most cheerful note: Wonderful! This was not simply a mannerism on his part. It was enough to meet Ricky once to realize that he was an incorrigible optimist. What was the source of his optimism? After almost 40 years, I have some clues, but no satisfactory answer.

Ricky did not have an easy start as a mathematician. When his uncle found out about his academic ambitions, his first reaction was: Are you nuts? How much money does a professor make? I can hire half a dozen people at such salaries! Start a business! But Ricky had no interest in money. His parents and many of their friends were Communists. During the McCarthy era, they were harassed by the authorities because of their political views. Ricky was one of the "red diaper babies." He shared his parents' dreams and wanted to make a difference. He always liked puzzles and chess, he excelled in mathematics, and above all he loved people. To become a teacher or a professor seemed like a natural goal for him. He was accepted to the $\mathrm{PhD}$ program in mathematics at NYU and started to do research in number theory under the direction of Harold N. Shapiro. After defending his thesis, he joined NYU as a professor. It must have been difficult for him to stay so close to his thesis advisor, who was not only a brilliant mathematician and engaging educator, but also had an imposing personality. It was the golden era of analytic number theory, and the field was full of extraordinary talents. It required a die-hard optimist like Ricky not to be discouraged by the grandeur of their achievements and to continue to do research. After spending a sabbatical in Montreal with Willy Moser and reuniting with his intellectual twin brother, Eli Goodman, he switched direction: the two of them started a lifelong collaboration in combinatorial geometry.

The rest is history. In an effort to understand and improve the Erdős-Szekeres theorem on convex polygons and to give a combinatorial description of other geometric configurations, they explored the notion of allowable sequences, which has become a

János Pach

pach@cims.nyu.edu

1 Rényi Institute, Budapest, Hungary

2 IST Austria, Vienna, Austria

3 Moscow Institute of Physics and Technology, Moscow, Russia 
standard tool in discrete geometry $[2,5,8,13]$. They defined and systematically studied order types of point sets and, applying powerful tools from real algebraic geometry, they found almost tight estimates for their numbers [3]. They extended their investigations to order types of families of convex bodies and, using topological techniques, they revitalized Helly theory for line transversals and, in general, for transversals of any fixed dimension $[4,6,11]$. They also explored many algorithmic consequences of their results. Apart from their scientific achievements, they left an equally important social legacy: In 1985, they launched the journal Discrete \& Computational Geometry, co-editing it for almost 25 years. It is hard to overstate the role of this journal in merging the two fields and creating a community of outstanding young researchers who have richly contributed to the new discipline. With the active participation of many excellent colleagues from the greater New York Area, they started a weekly Geometry Seminar at The Courant Institute, which has been one of the longest running seminars in the city. Today anyone can learn of the most important breakthroughs by following the papers posted on arXiv. In pre-Internet times, the internationally circulated announcements of the NYU Geometry Seminar, including the abstracts of the talks, played a similar role.

I know very few people who are so passionately interested in mathematics as Ricky was. In retrospect, it is quite clear that Ricky's enthusiastic response to my first geometric results motivated by algorithmic problems had a lasting effect on my mathematical taste and my choice of problems. It took some time before I realized that my influence on Ricky's work was also non-negligible. We shared a weakness: both of us wanted to impress the other. In 1982, when I visited New York for the first time, I had to meet Ricky. Coming from a country whose currency was not convertible, in the Western world I was poor as a church mouse. Through Ron Graham, Erdôs sent me 100 dollars to support my stay. Together with the 50 dollars I received for my talk at the CUNY Graduate Center, this enabled me to stay for more than a week. Ricky prepared for our meeting by taking a question from a letter written by Erdős, who he knew I collaborated with. What is the largest number $k=k(n)$ such that any set of $n$ points in the plane with minimum distance 1 has a subset of size $k$ in which the minimum distance is larger than 1 ? He was very happy to discover that it follows from the 4-color theorem that $k(n) \geq n / 4$. He published his observation as a note in JCT A [10]. (The problem is still open. Swanepoel [12] improved Ricky's bound to $8 n / 31$, while from the other direction the best known result can be found in [9].) Ricky often referred to this note as his "favorite paper". This was partially a joke, but he really loved surprising and elegant one line arguments. He knew by heart almost all problems in his friend Donald Newman's wonderful problem book [7], and he loved to entertain his students and friends with these questions. Just like Donald, he cherished "the days when math was fun (!), not the ponderous THEOREM, PROOF,..., but the whimsical, 'I've got a good problem'."

In May 1983, we organized the 2nd Austro-Hungarian Conference on Geometry in Siófok, Hungary. Ricky and Eli accepted our invitation. They had never been to an Eastern Bloc country, and decided to come a couple of days before the meeting. At that time I was staying in Erdôs's apartment in Budapest, which happened to be in the same building where my parents lived. After the death of his mother, Erdôs never used his apartment. He offered it to friends who needed temporary housing. I asked 
for his permission to accommodate Ricky and Eli. Of course, he happily agreed. There was only a couch in the apartment, so I borrowed a folding bed and moved back to my parents. On the morning when they were supposed to arrive, my mother woke me announcing that there were "two giants with huge suitcases walking up and down in front of our building." As soon as she said that, it struck me that Ricky and Eli would end up sleeping on the floor. I did not check this and politely they did not complain. They were 20 years older than me, but Ricky looked younger. (In fact, Eli has not changed much during the past four decades.) My friends could not believe that Ricky was almost 50. Together with Nancy, every summer he took long hiking and backtracking trips in national parks in the Western US. He was suntanned, strong, loud, always smiling, ready to connect with others. He was a master communicator. His secret was that he was truly interested in people, young and old. Ten years later, in New York, he had long phone conversations with my mother-in-law. They had no language in common, but they understood each other perfectly well. Ricky and Eli had a great time in Siófok. They established strong ties with a number of colleagues who they turned out to collaborate with for many years to come. Ricky had always been quite critical about Western-style capitalism. He was impressed by the Hungarian educational system and many other aspects of life under socialism. We had to argue with him, explaining that the Hungarian system had its serious shortcomings, too. Just like Eli and myself, he loved to argue. He had strong opinions, but I must admit that he was ready to revise them.

The conference ended with a reception. Neither Eli nor Ricky wanted to miss it, although next morning Eli had an early flight. I had a small and light East German car, a Trabant, with a plastic body. Shortly after midnight, I packed the two giants and their suitcases into my car, and we were heading to Budapest. We could not drive ten feet before the car literally broke and the engine fell out. It was hilarious, but we had no time for amusement: we had had to find some solution how to reach Ferihegy airport. Gerd Baron, a very friendly Austrian mathematician from Vienna, had a big Mercedes Benz, and he offered to take us to Budapest. After 15 mins on the highway, we hit and killed a deer and had to call the police. We were nervous, because all of us had had some alcohol during the party. No one was quite sure what the legal limit was. Ricky, who had diabetes, drank almost nothing. With no hesitation, he volunteered to sit behind the wheel and signed the official papers as the driver. We had to follow the police car to the nearest police station. There was a little problem: it took several minutes for Ricky to figure out how to start a Mercedes. The policemen were definitely puzzled. To tell the truth, I have also been puzzled ever since. How was it that he could not start the car? More importantly, how did he find the courage to deal with the police, feared by many, during his first visit to a communist country? I think I know the answer. Someone wanted to help him and in the process the person got into trouble. Ricky felt morally obliged to take responsibility for what happened. He was a very brave man who set very high standards for himself. When, many years later, I discussed this incident with him, he smiled: Time to time one has to do illegal things, just to stay in practice. Remember those who reported their friends to the authorities and the millions of Jews who followed the instructions all the way to the gas chambers!

In the early 90s, partially for personal reasons, Ricky fell in love with an emerging discipline between mathematics and computer science: algorithms in real algebraic 
geometry. Together with Marie-Françoise Roy and Saugata Basu, Ricky's strongest $\mathrm{PhD}$ student, he co-authored more than a dozen influential papers and the first monograph on the subject [1]. This was not his natural habitat in mathematics. But he was more than happy to return to the classroom as a student and refresh his somewhat rusty knowledge of algebra and analysis. He was a true scholar: he was not ashamed to admit if he did not understand an elementary statement. Sometimes he turned to Saugata for help when he got stuck during a lecture. As a proud Brooklynite, he liked to make fun of suburban life on the other side of the Hudson. After moving to Lori's house in Montclair, he admitted that he was unfair. He discovered the beauties of New Jersey and explored its cultural life.

To celebrate the scientific achievements of Ricky and Eli, in May 2001 we held a one-day conference at Courant Institute, "The Goodman-Pollack Two-thirds-of-acentury Fest." It was attended by many leading experts in discrete and computational geometry, members of a community Ricky and Eli helped to forge. The title referred to the average age of Ricky and Eli at the time. Ricky was recovering after a major stroke, and it looked unlikely that he would live long enough to celebrate his 70th birthday. Well, we were wrong: Ricky refused to surrender. Thanks to his strong will, vitality, and infinite love of people and mathematics, he lived and enriched our lives for another 17 years.

\section{References}

1. Basu, S., Pollack, R., Roy, M.-F.: Algorithms in Real Algebraic Geometry. Algorithms and Computation in Mathematics. Springer, Berlin (2003)

2. Goodman, J.E., Pollack, R.: A combinatorial perspective on some problems in geometry. Congr. Numer. 32, 383-394 (1981)

3. Goodman, J.E., Pollack, R.: Upper bounds for configurations and polytopes in $\mathbb{R}^{d}$. Discrete Comput. Geom. 1(3), 219-227 (1986)

4. Goodman, J.E., Pollack, R.: Hadwiger's transversal theorem in higher dimensions. J. Am. Math. Soc. 1(2), 301-309 (1988)

5. Goodman, J.E., Pollack, R.: Allowable sequences and order types in discrete and computational geometry. In: New Trends in Discrete and Computational Geometry. Algorithms and Combinatorics, vol. 10, pp. 103-134. Springer, Berlin (1993)

6. Goodman, J.E., Pollack, R.: The combinatorial encoding of disjoint convex sets in the plane. Combinatorica 28(1), 69-81 (2008)

7. Newman, D.J.: A Problem Seminar. Problem Books in Mathematics. Springer, New York and Berlin (1982)

8. Pach, J., Pinchasi, R., Sharir, M.: Solution of Scott's problem on the number of directions determined by a point set in 3-space. Discrete Comput. Geom. 38(2), 399-441 (2007)

9. Pach, J., Tóth, G.: On the independence number of coin graphs. Geombinatorics 6(1), 30-33 (1996)

10. Pollack, R.: Increasing the minimum distance of a set of points. J. Comb. Theory A 40(2), 450 (1985)

11. Pollack, R., Wenger, R.: Necessary and sufficient conditions for hyperplane transversals. Combinatorica 10(3), 307-311 (1990)

12. Swanepoel, K.J.: Independence numbers of planar contact graphs. Discrete Comput. Geom. 28(4), 649-670 (2002)

13. Ungar, P.: $2 N$ noncollinear points determine at least $2 N$ directions. J. Comb. Theory Ser. A 33(3), 343-347 (1982)

Publisher's Note Springer Nature remains neutral with regard to jurisdictional claims in published maps and institutional affiliations. 